\title{
Inhibitory effects of inhaled complex traditional Chinese medicine on early and late asthmatic responses induced by ovalbumin in sensitized guinea pigs
}

\author{
Hung-Chou Chang ${ }^{1,3}$, Cheng-Chung Gong ${ }^{1,2}$, Ji-Liang Chen ${ }^{1}$ and Oi-Tong Mak ${ }^{1,4^{*}}$
}

\begin{abstract}
Background: Many formulae of traditional Chinese medicines (TCMs) have been used for antiasthma treatment dating back many centuries. There is evidence to suggest that TCMs are effective as a cure for this allergenic disease administered via gastric tubes in animal studies; however, their efficacy, safety and side effects as an asthmatic therapy are still unclear.
\end{abstract}

Methods: In this study, guinea pigs sensitized with ovalbumin (OVA) were used as an animal model for asthma challenge, and the sensitization of animals by bronchial reactivity to methacholine (Mch) and the lgE concentration in the serum after OVA challenge were estimated. Complex traditional Chinese herbs (CTCM) were administered to the animals by nebulization, and the leukocytes were evaluated from bronchoalveolar lavage fluid (BALF).

Results: The results showed that inhalation of CTCM could abolish the increased lung resistance (13-fold increase) induced by challenge with OVA in the early asthmatic response (EAR), reducing to as low as baseline (1-fold). Moreover, our results indicated higher lgE levels (range, $78-83 \mathrm{ng} / \mathrm{ml}$ ) in the serum of sensitized guinea pigs than in the unsensitized controls $(0.9 \pm 0.256 \mathrm{ng} / \mathrm{ml})$. In addition, increased total leukocytes and higher levels of eosinophils and neutrophils were seen 6 hours after challenge, and the increased inflammatory cells were reduced by treatment with CTCM inhalation. The interleukin-5 (IL-5) level in BALF was also reduced by CTCM.

Conclusion: Our findings indicate a novel method of administering traditional Chinese medicines for asthma treatment in an animal model that may be more effective than traditional methods.

Keywords: asthma, Chinese medicine, guinea pig, nebulization, ovalbumin

\section{Background}

Bronchial asthma is a complex syndrome with many clinical symptoms. It is characterized by variable airflow obstruction, airway hyperresponsiveness and inflammation [1,2]. Provocation of the airway by inhaled allergens is followed by bronchospasm and airway smooth muscle thickening, and accumulation of eosinophils in mucosa and in bronchoalveolar lavage also occurs [1,3]. In addition, according to analyses of bronchial biopsies and lavage samples removed from allergen-exposed

\footnotetext{
* Correspondence: paul@mail.ncku.edu.tw

'Department of Life Sciences, National Cheng Kung University, Tainan 701, Taiwan

Full list of author information is available at the end of the article
}

asthmatics, contributing to the earlier asthmatic response (EAR) and late asthmatic response (LAR) after allergen challenge $[4,5]$, IgE-dependent activation of mast cells is present with degranulation and subsequent release of several mediators such as histamine, prostanoids and leukotrienes into the lumen of the airway. It is generally agreed that the EAR reaches a peak at about 5-30 min after challenge and lasts for around 2 hours, and in more than $50 \%$ of atopic asthmatic patients, the EAR is followed by the LAR, which occurs $4-12 \mathrm{~h}$ after challenge and lasts for several hours, even up to a couple of days [6]. The development of allergen-induced airway hyperresponsiveness is correlated with the LAR [7], in which an increase in the quantity of airway 
inflammatory cells, particularly eosinophils, can be observed in induced sputum $[4,6]$. A number of small animal models such as mice, rats and guinea pigs have been developed for asthma study, in which the LAR occurs in the airway of sensitized animals after exposure to antigens. Of the animal models, the guinea pig is generally the preferred model because the responses to a variety of contractile and relaxant substances are similar to those of humans $[8,9]$.

For the treatment of asthma, sodium cromoglycate and $\beta_{2}$-adrenoceptor agonist inhibit the EAR. On the other hand, both the LAR and associated airway hyperresponsiveness are inhibited by sodium cromoglycate and corticosteroids, not by $\beta_{2}$-adrenoceptor agonists [10-12]. In addition, in most cases, mild-to-moderate asthma can be controlled by inhalational steroids; however, long-term steroid therapy is often associated with multiple side effects that have long-term repercussions on one's health [13]. In contrast to western medicines, Chinese herbs have been used to treat asthma for many centuries, some of which have been proven to inhibit the EAR and LAR in asthma patients subjected to specific allergens [8,14-16]. Freeze-dried powder of a traditional Chinese medicine was administered via a gastric tube before or after challenge in this study. The results showed that the Chinese medicine attenuated the increased respiratory resistance and the amount of eosinophilia induced by the allergens [8,14-16]; however, the mechanisms are unclear. In this study, a formula of complex traditional Chinese medicines (CTCM) was used. This formula contains eight herbs and has been generally used to treat asthmatic patients in Chinese medicine clinics. The CTCM was delivered by inhalation, which we expected to have a better effect than oral administration as the drug can directly and rapidly reach the airways.

In this study, we evaluated the effects of CTCM on the change in the mean pulmonary resistance and the inflammatory responses of the airway in ovalbumin (OVA)-sensitized guinea pigs. The CTCM was nebulized and inhaled autonomically by the animals under anesthesia. The inhalation route is new for CTCM. The effect of local treatment with CTCM on the asthmatic response in sensitized guinea pigs was then investigated.

\section{Methods}

\section{Sensitization and challenge of animals}

The study protocol was approved by the Institutional Review Board of the National Cheng Kung University. Sensitization of the guinea pigs was performed as described in previous studies $[17,18]$ with some modification. Briefly, specific pathogen-free Dunkin-Hartley male guinea pigs (GP) weighing 400-600 g, obtained from the National Laboratory Animal Center, Taipei,
Taiwan, were used in this study. The animals were actively IgE-sensitized to OVA (grade VI; Sigma-Aldrich, St. Louis, MO, USA). On day one, $100 \mu$ g OVA with 10 $\mathrm{mg}$ of aluminum hydroxide $\left(\mathrm{Al}(\mathrm{OH})_{3}\right)$ gel in $0.5 \mathrm{ml}$ of normal saline were injected intraperitoneally. A booster sensitization $(50 \mu \mathrm{g}$ of OVA and $5 \mathrm{mg}$ of aluminum hydroxide gel in $0.25 \mathrm{ml}$ normal saline) was administered on day 7. The sensitized guinea pigs were then exposed to an aerosol containing 1\% OVA (w/v) for 20 sec on day 14. Animals were anesthetized with urethane ( $2 \mathrm{~g} / \mathrm{kg}$ i.p.), intubated, and challenged by inhalation of nebulized 1\% OVA (w/v) for $20 \mathrm{sec}$ on day 21 . Unsensitized guinea pigs were treated in the same way with normal saline.

\section{Preparation of the Chinese herbal formula}

In this study, we used a CTCM formula that is used by traditional Chinese medical physicians for the treatment of asthmatic patients. The composition of the CTCM was similar to the xiao-qing-long-tang (XQLT) formula, a formula of Chinese medicine that has been proven to suppress the EAR and LAR in sensitized guinea pigs via oral administration [14]. There are eight common Chinese herbs in this CTCM: Ephedrae herba (stem of Ephedrae sinica Stapf, 18.75 g), Paeoniae radix (root of Paeoniae lactiflora Pallas, 18.75 g), Glycyrrhizae radix (root and rhizome of Glycyrrhiza uralensis Fischer, 18.75 g), Cinnamonomi ramulus (cortex of Cinnamomum cassia Blume, $18.75 \mathrm{~g}$ ), Asari herba cum radice (whole plant of Asarum sieboldii Miq, $18.75 \mathrm{~g}$ ), bitter apricot seed ( Prunus armeniaca (Magnoliaceae), 18.75 g), Common perilla stem (Perilla frutescens (Labiatae), $18.75 \mathrm{~g}$ ), and Ledebouriella root (Saposhnikovia divaricate (Apiaceae), $18.75 \mathrm{~g}$ ). The herbs were purchased from a government-approved herbal company, Hong Cheng Chinese Medicine (Tainan, Taiwan). All air-dried herbs were submerged in $800 \mathrm{ml}$ distilled water for 30 min, then heated to boiling point and maintained at about $103^{\circ} \mathrm{C}$ for $15 \mathrm{~min}$. The resulting extract was filtered through a $0.45-\mathrm{mm}$ filter and concentrated to approximately $350 \mathrm{ml}$. The concentrated extract was finally lyophilized to yield $21 \mathrm{~g}$ dried powder, which was maintained at $4^{\circ} \mathrm{C}$ for storage. The dried extract was dissolved in saline before use. For inhalation, three concentrations $(0.03,0.06$ and $0.09 \mathrm{~g} / \mathrm{ml})$ of CTCM were tested, and the latter two concentrations showed a similar inhibition effect. Therefore, a CTCM concentration of $0.06 \mathrm{~g} / \mathrm{ml}$ was used in this study.

\section{The airway hyperresponsiveness (AHR) of Mch}

This study examined the dysfunction underlying AHR, including two major physiopathological mechanisms: hypersensitivity and hyperreactivity. Hypersensitivity is a shift to the left of the bronchoconstrictor dose-response 
curve, and hyperreactivity is an increased slope of the curve. The bronchial hyperresponsiveness of guinea pigs to Mch was recorded to assess the sensitization of the animals. The underlying contributors to airway responsiveness were measured on the basis of the respiratory system resistance to saline and increasing intravenous doses of Mch, as per the method described elsewhere in detail by others [19-21] with some modification. Briefly, to achieve optimal sensitization, we used increasing doses of Mch, at 12.5, 50, 100, 250, and $500 \mu \mathrm{g} / \mathrm{kg}$.

\section{Experimental design and administration}

Respiratory resistance $\left(\mathbf{R}_{\mathbf{L}}\right)$ was measured before treatment as a baseline control. $\mathbf{R}_{\mathbf{L}}$ was subsequently recorded after challenge every $5 \mathrm{~min}$ in the first hour and every $30 \mathrm{~min}$ in the following 5 hours. The guinea pigs were randomly divided into four groups:

1) NSGP $(n=10)$ : unsensitized GP challenged with OVA.

2) SGP $(n=10)$ : sensitized GP challenged with OVA.

3) MSGP $(n=10)$ : sensitized GP treated with $0.06 \mathrm{~g} /$ $\mathrm{ml} \mathrm{CTCM}$ for $5 \mathrm{~min}$ by nebulization, followed by OVA challenge (at $5 \mathrm{~min}$ after CTCM nebulization).

4) SMGP $(n=10)$ : sensitized GP challenged with OVA, followed by treatment with $0.06 \mathrm{~g} / \mathrm{ml} \mathrm{CTCM}$ for $5 \mathrm{~min}$ by nebulization (at $10 \mathrm{~min}$ after OVA challenge).

\section{Measurement of airway responses to OVA challenge}

Guinea pigs were anesthetized with urethane $(2 \mathrm{~g} / \mathrm{kg}$; i. p.), tracheostomized, and cannulated with polyethylene tubing (PE210; Scientific Commodities, Lake Havasu City, AZ, USA), then a catheter was advanced through the mouth into the lower end of the esophagus. Pleural pressure was measured via the esophageal catheter. The lateral pressure in the trachea, transpulmonary pressure (the difference between the tracheal and pleural pressure), and $R_{L}$ were measured as described in a previous study [22]. A pneumotachograph (Series 1110; Hans Rudolph, Shawnee, KS, USA) connected to the proximal end of the endotracheal tube was used to measure $R_{L}$. The respiratory volume was obtained by digital integration of the flow signal, and $R_{L}$ was calculated from the transpulmonary pressure and flow rates at isovolumetric points [22]. Samples of 5-10 breaths were analyzed for each determination of $\mathrm{R}_{\mathrm{L}}$. In addition, we measured the underlying contributors to airway responsiveness, including airway reactivity (i.e., the slope of the increase in the mean pulmonary flow resistance $\left[R_{L}\right]$ for a given increase in Mch dose), airway sensitivity (i.e., the lowest dose of Mch that produced bronchoconstriction), and the maximum inducible bronchoconstriction (maximum $R_{L}$ ). These components of airway responsiveness were measured based on the response of $R_{L}$ to saline and increasing intravenous doses of Mch.

\section{lgE in serum}

Blood was withdrawn from the guinea pigs from the heart $6 \mathrm{hr}$ after challenge. The IgE level specific to OVA in the serum was estimated using commercial ELISA kits (MARUKO, Nagoya, Japan).

\section{Bronchoalveolar lavage}

Bronchoalveolar lavage was performed $6 \mathrm{~h}$ after OVA challenge. Lung lavage was performed gently using $3 \mathrm{ml}$ of PBS (phosphate-buffered saline) at $37^{\circ} \mathrm{C}$. The tracheal cannula was clamped, and the thorax was massaged for $60 \mathrm{~s}$ before the bronchoalveolar lavage fluid (BALF) was recovered. This process was repeated once. The recovered lavage samples were cooled on ice and centrifuged at $150 \times \mathrm{g}$ for $10 \mathrm{~min}$ at $4^{\circ} \mathrm{C}$. Approximately $4 \mathrm{~mL}$ of fluid were recovered from each sample of BALF, thus maintaining a roughly equal amount of BALF among the treatment groups. The total cell count and cell viability were estimated using a hemacytometer and trypan blue staining. Slides were prepared using a Cytospin model II (Shandon, Pittsburgh, PA, USA). The differential cell count was assessed with Liu's stain. A total of 500 cells were assessed and classified into mononuclear cells, neutrophils, or eosinophils based on the standard morphologic criteria.

\section{IL-5 in BALF}

IL-5 in BALF supernatant was assessed using commercial ELISA kits (R\&D Systems, Minneapolis, MN, USA).

\section{Statistical Analysis}

The data from 10 animals in each group were collected, and the results are expressed as mean \pm SEM (standard error of the mean). Repeated measures ANOVA or oneway ANOVA was performed to compare the statistical difference between groups. Differences with $P<0.05$ were judged to be significant.

\section{Results}

\section{Effects of Mch on the airway}

The $R_{L}$ of the guinea pigs was dependent on the dose of Mch. However, the curve of $R_{L}$ in relation to Mch had a greater slope for the sensitized animals than that for the unsensitized animals (Figure 1). Therefore, the results suggested that the sensitized guinea pigs exhibited enhanced airway responsiveness to Mch.

IgE in the serum of unsensitized and OVA-sensitized guinea pigs after challenge

In the OVA-sensitized GP after challenge (with or without CTCM nebulization), the average OVA-specific IgE in the serum of the sensitized guinea pigs in the SGP group was $78.0 \pm 17.83 \mathrm{ng} / \mathrm{ml}$, and the average IgE levels of the MSGP and SMGP groups were about 83.4 $\pm 19.57 \mathrm{ng} / \mathrm{ml}$ and $81.9 \pm 10.79 \mathrm{ng} / \mathrm{ml}$, respectively. 


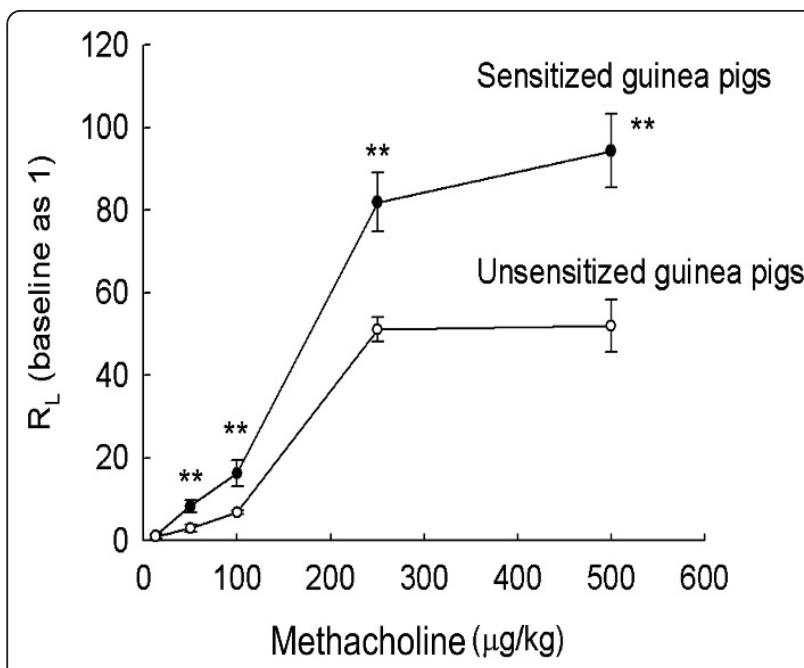

Figure 1 Airway responsiveness methods. Pulmonary airflow resistance $\left(R_{L}\right)$ was measured in response to increasing doses of intravenous methacholine (Mch). Using the resulting $R_{L}-M c h$ dose-response curve, indices of airway reactivity (Slope $R_{L}$ ), airway sensitivity, the lowest dose producing bronchoconstriction (Break $R_{L}$ ) and the maximal degree of bronchoconstriction (Max $R_{L}$ ) were measured (repeated measures ANOVA with a Mauchly post-hoc test, sensitized vs. unsensitized; ${ }^{*} P<0.01$ ).

These values were all significantly higher than the level in the unsensitized control group, which was approximately $0.9 \pm 0.256 \mathrm{ng} / \mathrm{ml}$ (Figure 2).

\section{$R_{L}$ of guinea pigs after challenge}

The respirator resistance $\left(\mathbf{R}_{\mathbf{L}}\right)$ was monitored at regular intervals for up to $6 \mathrm{hr}$ after aerosol inhalation of antigens (Figure 3A). Aerosolized OVA caused immediate bronchoconstriction, which peaked at 15 min among the sensitized guinea pigs. In the SGP group, inhalation of OVA increased the $\mathrm{R}_{\mathrm{L}}$ by 13 -fold that of the control. In addition, the EAR was also exhibited in the SGP group. The EAR started immediately after OVA challenge and reached a maximum about 15 min after challenge with OVA. At any point in time after challenge, the $R_{L}$ in the SGP group was at least 2 -fold that in the NSGP group $(P$ $<0.01$ at $15 \mathrm{~min}$ ). At around $6 \mathrm{hr}$ after challenge, another increase in $\mathrm{R}_{\mathrm{L}}$ of a moderate level was observed.

Effect of CTCM on allergen-induced respiratory resistance For the animals pre-treated with CTCM (the MSGP group), $\mathrm{R}_{\mathrm{L}}$ reduced to the baseline level of the control group after challenge (Figure $3 \mathrm{~A}$ ). The respirator resistance at each time point from 5 min to $1 \mathrm{~h}$ after challenge was significantly lower in the MSGP group than in the control SGP group $(P<0.01$ at $10,15,20 \mathrm{~min})$ (Figure 3B). On the other hand, as the maximum increase in $\mathrm{R}_{\mathrm{L}}$ was observed 15 min after challenge, we therefore examined the effect of post-treatment with

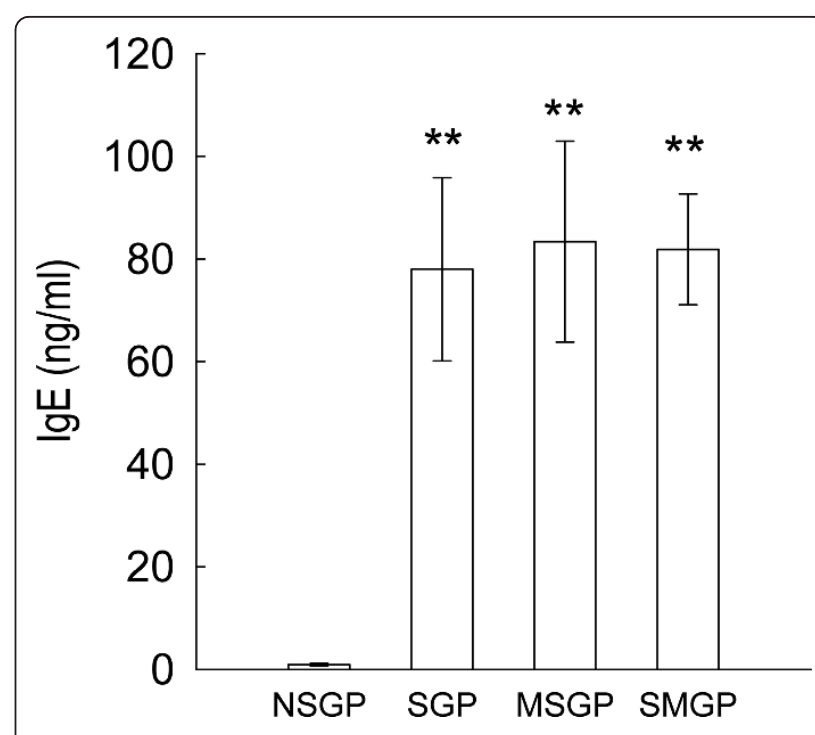

Figure $2 \mathrm{lgE}$ in the serum of guinea pigs. Statistical significance (one-way ANOVA with a Duncan post-hoc test, **P $<0.01)$ represents a comparison between the sensitized groups (SGP, MSGP and SMGP) and the control group (NSGP). Each column represents the mean of the data from 10 animals and the restical bars represent the standard deviation. NSGP:

unsensitized animals with challenge; SGP: sensitized animals with challenge; MSGP: sensitized animals with CTCM treatment 5 min before challenge; SMGP: sensitized animals with CTCM treatment 10 min after challenge.

CTCM 10 min after challenge. Interestingly, the results showed that for the animals post-treated with CTCM (SMGP group), CTCM treatment almost completely impeded the early OVA-induced $\mathrm{R}_{\mathrm{L}}$ response immediately (data not shown in Figure $3 \mathrm{~A}$ as the line of the SMGP group overlapped with that of the MSGP group). The $\mathrm{R}_{\mathrm{L}}$ of the SMGP group was increased at 5 and 10 min, but the increase in $\mathrm{R}_{\mathrm{L}}$ was attenuated after treatment with CTCM, and $\mathrm{R}_{\mathrm{L}}$ had decreased to the baseline levels of the control and MSGP groups 15 min after challenge $(P<0.01$ at $15 \mathrm{~min}$; Figure $3 \mathrm{~B})$.

\section{Effect of CTCM on OVA-induced inflammatory cells infiltration in BALF}

We next recovered inflammatory cells from BALF obtained from the animals at $6 \mathrm{hr}$. As compared with the non-immunized group, OVA caused a significant increase in inflammatory cells in the immunized group without CTCM treatment (SGP) (Figure 4). There was also a significant increase of eosinophils at this time point after OVA challenge, while CTCM treatment, either before or after OVA challenge, had an inhibitive effect on eosinophil infiltration in BALF, as shown in Figure 5. As compared with the immunized group (SGP), our results showed that CTCM treatment significantly reduced the increase in eosinophils in BALF 


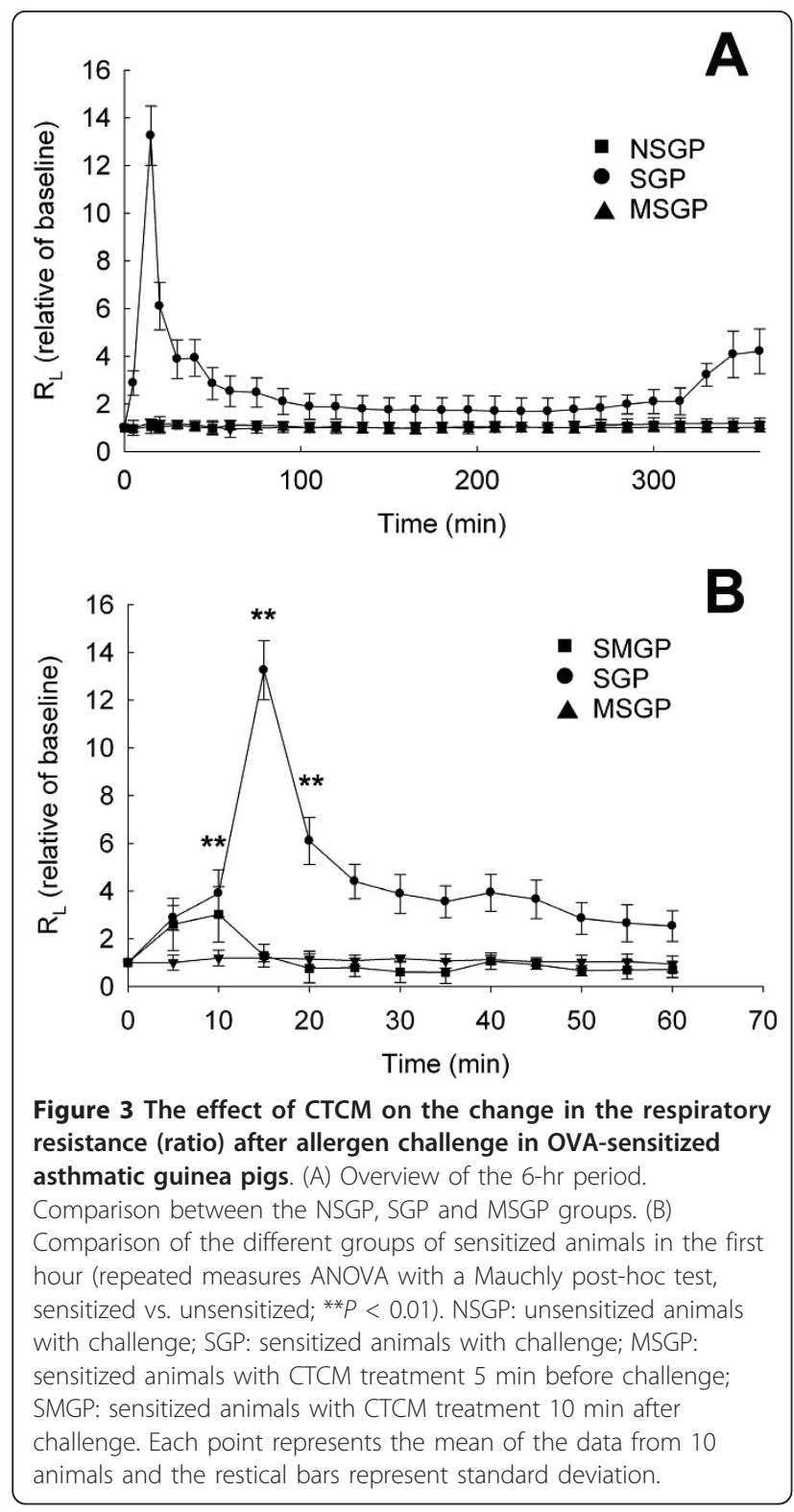

at $6 \mathrm{~h}(P<0.01)$ after challenge. In addition, CTCM treatment also inhibited the increase in neutrophils $(P$ $<0.01)$ in both the CTCM pre- and post-treated groups.

\section{IL-5 in the BALF of the guinea pigs}

The average IL-5 level in the BALF of the unsensitized guinea pigs (NSGP group) was about $43 \mathrm{pg} / \mathrm{ml}$, and the average IL-5 level of the SGP group was increased by OVA to $135 \mathrm{pg} / \mathrm{ml}$. In the MSGP and SMPG groups, the average IL-5 levels were decreased by CTCM inhalation to $64 \mathrm{pg} / \mathrm{ml}$ and $88 \mathrm{pg} / \mathrm{ml}$, respectively (Figure 6).

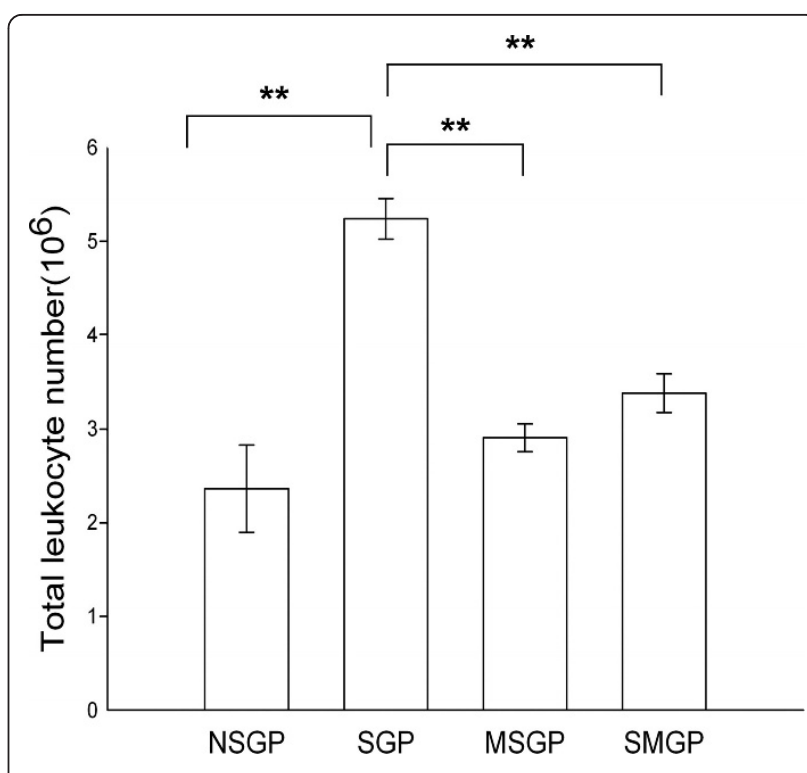

Figure 4 The effect of CTCM on the change in the total leukocyte cell number $6 \mathrm{hr}$ after allergen challenge in OVAsensitized asthmatic guinea pigs. Each column represents the mean of the data from 10 animals and the restical bars represent standard deviation (one-way ANOVA with a Duncan post-hoc test, $\left.{ }^{* *} P<0.01\right)$. NSGP: unsensitized animals with challenge; SGP: sensitized animals with challenge; MSGP: sensitized animals with CTCM treatment 5 min before challenge; SMGP: sensitized animals with CTCM treatment 10 min after challenge.

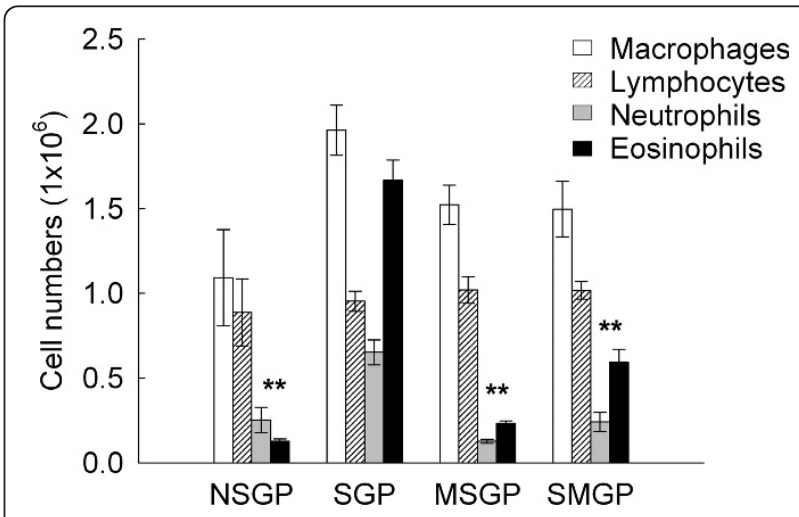

Figure 5 The effects of CTCM on the changes in differential cell counts after allergen challenge in OVA-sensitized asthmatic guinea pigs. CTCM treatment before or after OVA challenge decreased the cells numbers of eosinophils and neutrophils (MSGP or SMGP vs. SGP; one-way ANOVA with a Duncan post-hoc test, $\left.{ }^{* *} P<0.01\right)$. Each group represents the mean of the data from 10 animals and the restical bars represent standard deviation. NSGP: unsensitized animals with challenge; SGP:

sensitized animals with challenge; MSGP: sensitized animals with CTCM treatment 5 min before challenge; SMGP: sensitized animals with CTCM treatment 10 min after challenge. 


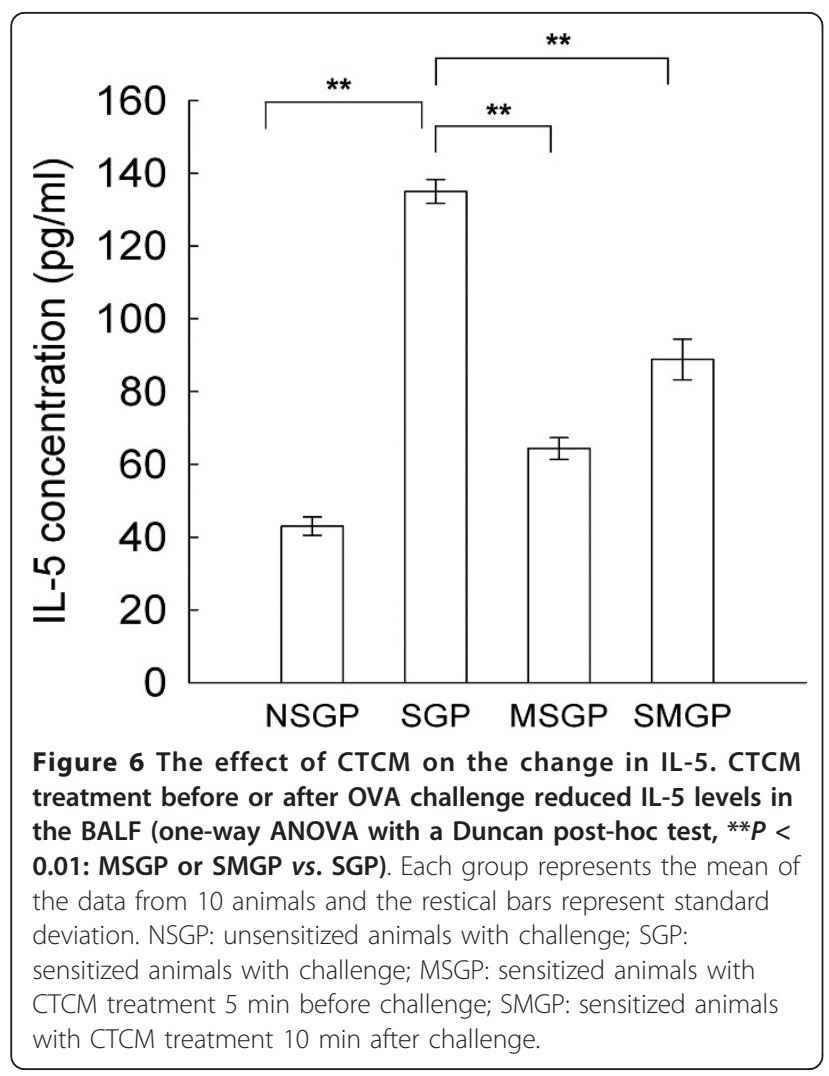

\section{Discussion}

In this study, we used an OVA-sensitized guinea pig model to investigate the effect of inhalation of CTCM on the early and late antigen-induced airway responses. Guinea pigs have been used as an animal model for asthmatic research for many years. Different sensitization processes may induce different severities of antigen reactions. Booster sensitization by an aerosolized antigen has been widely used in recent years, as this antigen delivery route is similar to the natural physiological way, and this method can elicit responses including elevated levels of allergen-specific IgE, eosinophilic airway inflammation, and AHR [8,14-16]. On the other hand, delivery of medication directly to the airways has a quicker action than the oral route, as the drug can act immediately upon the target area. Therefore, inhalation therapy is generally thought to be the most effective and safe route in comparison with other forms of administration of medications for the treatment of asthma.

Bronchial hyperreactivity to both histamine and Mch has been well established and is used in the clinical diagnosis of asthma [23,24]. Mch is believed to have little or no irritant effect but to act directly on the cholinergic receptors innervated in smooth muscle [25]. In the test of Mch, this nonspecific stimulator induced a larger $R_{L}$ in the sensitized subjects than the unsensitized ones. The slope of the dose and $\mathrm{R}_{\mathrm{L}}$ curve in the sensitized groups shifted to the left, as has been observed in other studies [26]. The IgE levels in the serum of the animals in the sensitized groups were also higher than those in the unsensitized animals. These results suggested that the process of sensitization was successful, and that a sensitized model was established. Furthermore, there was no significant difference in the IgE level in the serum between the animals treated with CTCM (MSGP and SMGP groups) and those without CTCM treatment (SGP group). This might be due to the guinea pigs having been sensitized to OVA three times in a total of 21 days; therefore, specific anti-OVA IgE was induced to very high levels. In addition, as the CTCM was applied directly to the airway, it therefore had no significant effect on the level of serum IgE. The results showed that the guinea pigs in the CTCM-treated groups were indeed sensitized and that bronchoconstriction was abolished by CTCM.

Chinese herbs have been used for the treatment of asthmatic patients for centuries. Most of the Chinese herbs used for the treatment of bronchial asthma are either administered orally or through a gastric tube for research purposes. For example, several studies have demonstrated the anti-asthmatic effects of traditional Chinese medicine formulas such as XQLT by administering the medicine via the gastric route to guinea pigs [14-16], and simplified herbal medicine treatment also reduced several asthma features in a mouse model $[27,28]$. Currently, many of the western medicines used for the treatment of asthma are inhaled. Although several CTCM formulas have been shown to relieve asthma symptoms by oral administration, no study has been found in the English literature in which CTCM was administered in inhaled form to validate its efficacy. Administration of CTCM by inhalation, such as the use of portable bronchodilator sprays, which are already widely used in asthma treatment, is convenient and relatively simple. Inhalation it is expected to have a better effect than oral administration, as the CTCM can directly and rapidly reach the airways. For practical application, it is possible to use an aerosol inhaler to deliver CTCM into the lungs.

In this study, we demonstrated that CTCM administered in nebulized form through the intratracheal route is capable of inhibiting both the early and late asthmatic responses and the influx of inflammatory cells into the airways of guinea pigs following bronchial antigen challenge. The results indicate that this CTCM is a bronchoprotective substance and exerts an anti-inflammatory effect in OVA-sensitized guinea pigs. This is the first time that Chinese medicines have been used in the treatment of bronchial asthma by inhalation in an animal model. The EAR and LAR to OVA challenge in 
guinea pigs were observed to be dramatically inhibited by CTCM treatment in the present study.

When anti-asthmatic drugs are administered prior to antigen challenge, sodium cromoglycate inhibits both the EAR and LAR, whereas both the LAR and associated airway hyperresponsiveness are inhibited by sodium cromoglycate and corticosteroids [29]. Albuterol, a $\beta_{2}$-agonist, blocks the EAR but neither inhibits the LAR nor affects eosinophil infiltration [29]. Dexamethasone inhibits the LAR, but not the EAR, and inhibits the increase in eosinophils in BALF $24 \mathrm{hr}$ after antigen challenge [30]. In this study, the effects of CTCM treatment on antigen-induced airway responses were investigated, and our results showed inhibition of the increased $R_{L}$ and eosinophilia by CTCM. We have demonstrated that nebulized CTCM exerts both a bronchodilator and antiinflammatory activity in OVA-sensitized guinea pigs. Inhalation of CTCM both $5 \mathrm{~min}$ before challenge (MSGP group) and $10 \mathrm{~min}$ after challenge (SMGP group) significantly inhibited the EAR and the increase of inflammatory cells in the airways, including eosinophils and neutrophils. These findings suggest that CTCM can be used as an anti-asthmatic agent and is useful for the prevention or treatment of asthma.

Many compounds extracted from herbs have demonstrated anti-oxidant properties and anti-inflammatory effects, which can lead to a decrease in allergic tissue injury. For example, green tea extract has been reported to have an anti-inflammatory activity that inhibits iNOS expression by suppressing IFN- $\gamma$-elicited STAT-1 activation [31], and aqueous extract of Arbutus unedo L. has been shown to attenuate carrageenan-induced lung inflammatory injury, which is associated with the inhibition of IL-6 production, reduction of STAT-1 and STAT-3 expression, and downregulation of iNOS and ICAM-1 mRNA expression [32]. It is still unclear whether the CTCM used in this study has a similar mechanism to the mechanisms observed for other herbal extracts that possess inhibition properties to transcription factors or have direct effects on proinflammatory genes. This is worthy of further investigation to explore the mechanisms involved.

Many studies have shown that development of the LAR is associated with recruitment of eosinophils into the airway, which presumably cause cellular activation and bronchoconstriction [33-36]. These reactions are due to the release of cytotoxic granular-associated proteins by eosinophils, including major basic protein, eosinophil cationic protein, and eosinophil peroxidase, which have a profound effect on the airway $[16,37,38]$. Furthermore, eosinophil activation results in the release of other mediators, such as leukotriene $\mathrm{C}_{4}$ and plateletactivating factor, which can cause contraction of the airway smooth muscles $[39,40]$. In the present study, an increase in eosinophils in response to OVA challenge was observed, and the administration of CTCM inhibited the eosinophilia in OVA-sensitized guinea pigs. IL-5 is an important cytokine for eosinophil development and activation, and secretion of IL-5 causes eosinophil recruitment into the airways during the allergic airway response [41,42]. The results of this study showed that IL-5 in BALF was induced by OVA, and that the CTCM could reduce the increased IL-5.

Although the presence of eosinophils in airway inflammation is recognized as an important event, it does not fully explain the inflammation observed in asthma. Increased numbers of neutrophils have been found in patients with acute or persistent asthma compared with controls $[43,44]$. Many studies have also reported that increased neutrophil levels may contribute to exacerbation in asthma patients exposed to allergens, and airway neutrophils may be associated with asthma severity [45]. Although it is still controversial, there is increasing evidence to support the hypothesis that neutrophils are important in the pathophysiology of asthma. Our results also demonstrated that CTCM inhibited the OVAinduced increase of neutrophils, which suggests that CTCM inhalation might block neutrophil recreation to the site of the allergic reaction.

\section{Conclusion}

In conclusion, we have demonstrated for the first time that nebulized CTCM is effective against early-phase airflow obstruction in anaesthetized sensitized guinea pigs challenged by OVA inhalation. The OVA-induced increases in airway eosinophils and neutrophils and the increased levels of IL-5 in BALF in the late phase were also inhibited by nebulized CTCM treatment. Our results suggest that there may be two anti-asthmatic mechanisms for CTCM, a bronchodilator effect resulting from its stimulation of $\beta_{2}$-receptors on bronchial smooth muscles, and an ability to inhibit the increased IL-5 and eosinophil infiltration into the airway. The precise mechanism of nebulized CTCM in asthma remains to be elucidated, but the effect of reducing early and late antigen-induced airway responses highlights a possible novel way of administering CTCM for asthma treatment.

\section{Acknowledgements}

The authors wish to thank Dr Shun-Fen Tzeng (Department of Life Sciences, National Cheng Kung University) for her support.

\section{Author details}

'Department of Life Sciences, National Cheng Kung University, Tainan 701, Taiwan. ${ }^{2}$ Department of Medical Technology, Chung Hwa University of Medicine Technology, Tainan 717, Taiwan. ${ }^{3}$ Office of the Principal, Tainan Tzu-Chi Senior High School, Tainan 708, Taiwan. ${ }^{4}$ Department of Healthcare Department, University of Kang Ning, Tainan 709, Taiwan. 


\section{Authors' contributions}

HCC conceived and designed the study and carried out many of the culture experiments, analyzed and interpreted the data, and drafted the manuscript. CCG and JLC performed some of the experiments and data analysis, and contributed to the drafting of the manuscript. OTM was involved in the conception and design of the study and the supervision of experiments. All authors read the manuscript, contributed to its correction, and approved the final version.

\section{Competing interests}

The authors declare that they have no competing interests.

Received: 21 March 2011 Accepted: 24 September 2011

Published: 24 September 2011

\section{References}

1. Kay AB: Asthma and inflammation. J Allergy Clin Immunol 1991, 87:893-910.

2. Santing RE, Olymulder CG, Zaagsma J, Meurs H: Relationships among allergen-induced early and late phase airway obstructions, bronchial hyperreactivity, and inflammation in conscious, unrestrained guinea pigs. J Allergy Clin Immunol 1994, 93:1021-1030.

3. Fireman P: Understanding asthma pathophysiology. Allergy Asthma Proc 2003, 24:79-83.

4. Holgate ST, Kay AB: Mast cells, mediators and asthma. Clin Allergy 1985, 15:221-234.

5. Spina D, Shah S, Harrison S: Modulation of sensory nerve function in the airways. Trends Pharmacol Sci 1998, 19:460-466.

6. Pelikan Z, Pelikan-Filipek M: The late asthmatic response to allergen challenge-Part I. Ann Allergy 1986, 56:414-420.

7. Hargreave FE: Late-phase asthmatic responses and airway inflammation J Allergy Clin Immunol 1989, 83:525-527.

8. Kao ST, Chang CH, Chen YS, Chiang SY, Lin JG: Effects of Ding-Chuan-Tang on bronchoconstriction and airway leucocyte infiltration in sensitized guinea pigs. Immunopharmacol Immunotoxicol 2004, 26:113-124.

9. Fedan JS, Frazer DG: Influence of epithelium on the reactivity of guinea pig isolated, perfused trachea to bronchoactive drugs. $J$ Pharmacol Exp Ther 1992, 262:741-750.

10. Booij-Noord H, Orie NG, De Vries K: Immediate and late bronchial obstructive reactions to inhalation of house dust and protective effects of disodium cromoglycate and prednisolone. J Allergy Clin Immunol 1971, 48:344-354.

11. Cockcroft DW, Murdock KY: Comparative effects of inhaled salbutamol, sodium cromoglycate, and beclomethasone dipropionate on allergeninduced early asthmatic responses, late asthmatic responses, and increased bronchial responsiveness to histamine. J Allergy Clin Immunol 1987, 79:734-740.

12. Hegardt B, Pauwels R, Van Der Straeten M: Inhibitory effect of KWD 2131, terbutaline, and DSCG on the immediate and late allergen-induced bronchoconstriction. Allergy 1981, 36:115-122.

13. Clark TJH, Godfrey S, Lee TH, Thomson NC: Asthma. Asthma New York: Arnold; 2000, 319

14. Kao ST, Lin CS, Hsieh CC, Hsieh WT, Lin JG: Effects of xiao-qing-long-tang (XQLT) on bronchoconstriction and airway eosinophil infiltration in ovalbumin-sensitized guinea pigs: in vivo and in vitro studies. Allergy 2001, 56:1164-1171.

15. Kao ST, Yeh TJ, Hsieh CC, Shiau HB, Yeh FT, Lin JG: The effects of Ma-XingGan-Shi-Tang on respiratory resistance and airway leukocyte infiltration in asthmatic guinea pigs. Immunopharmacol Immunotoxicol 2001, 23:445-458.

16. Kao ST, Yeh TJ, Hsieh CC, Yeh FT, Lin JG: Effect of San-Ao-Tang on immediate and late airway response and leukocyte infiltration in asthmatic guinea pigs. Immunopharmacol Immunotoxicol 2000, 22:143-162.

17. Lewis CA, Broadley KJ: Airway hyper- or hyporeactivity to inhaled spasmogens $24 \mathrm{~h}$ after ovalbumin challenge of sensitized guinea-pigs. Br J Pharmacol 1995, 116:2351-2358.

18. Toward TJ, Broadley KJ: Early and late bronchoconstrictions, airway hyper-reactivity, leucocyte influx and lung histamine and nitric oxide after inhaled antigen: effects of dexamethasone and rolipram. Clin Exp Allergy 2004, 34:91-102

19. Inman MD, Ellis R, Wattie J, Denburg JA, O'Byrne PM: Allergen-induced increase in airway responsiveness, airway eosinophilia, and bone- marrow eosinophil progenitors in mice. Am J Respir Cell Mol Biol 1999, 21:473-479.

20. Leigh R, Ellis R, Wattie J, Southam DS, De Hoogh M, Gauldie J, O'Byrne PM, Inman MD: Dysfunction and remodeling of the mouse airway persist after resolution of acute allergen-induced airway inflammation. Am J Respir Cell Mol Biol 2002, 27:526-535.

21. Volgyesi GA, Tremblay LN, Webster P, Zamel N, Slutsky AS: A new ventilator for monitoring lung mechanics in small animals. J Appl Physiol 2000, 89:413-421.

22. Abraham WM, Bourdelais AJ, Sabater JR, Ahmed A, Lee TA, Serebriakov I, Baden DG: Airway responses to aerosolized brevetoxins in an animal model of asthma. Am J Respir Crit Care Med 2005, 171:26-34.

23. Chatham M, Bleecker ER, Smith PL, Rosenthal RR, Mason P, Norman PS: A comparison of histamine, methacholine, and exercise airway reactivity in normal and asthmatic subjects. Am Rev Respir Dis 1982, 126:235-240.

24. Bhagat RG, Grunstein MM: Comparison of responsiveness to methacholine, histamine, and exercise in subgroups of asthmatic children. Am Rev Respir Dis 1984, 129:221-224.

25. Scanlon RT: Asthma: a panoramic view and a hypothesis. Ann Allergy 1984, 53:203-212.

26. Leigh R, Ellis R, Wattie JN, Hirota JA, Matthaei KI, Foster PS, O'Byrne PM, Inman MD: Type 2 cytokines in the pathogenesis of sustained airway dysfunction and airway remodeling in mice. Am J Respir Crit Care Med 2004, 169:860-867.

27. Busse PJ, Schofield B, Birmingham N, Yang N, Wen MC, Zhang T, Srivastava K, Li XM: The traditional Chinese herbal formula ASHMI inhibits allergic lung inflammation in antigen-sensitized and antigen-challenged aged mice. Ann Allergy Asthma Immunol 2010, 104:236-246.

28. Zhang T, Srivastava K, Wen MC, Yang N, Cao J, Busse P, Birmingham N, Goldfarb J, Li XM: Pharmacology and immunological actions of a herbal medicine ASHMI on allergic asthma. Phytother Res 2010, 24:1047-1055

29. Hutson PA, Holgate ST, Church MK: The effect of cromolyn sodium and albuterol on early and late phase bronchoconstriction and airway leukocyte infiltration after allergen challenge of nonanesthetized guinea pigs. Am Rev Respir Dis 1988, 138:1157-1163.

30. Matsumoto T, Ashida Y, Tsukuda R: Pharmacological modulation of immediate and late airway response and leukocyte infiltration in the guinea pig. J Pharmacol Exp Ther 1994, 269:1236-1244.

31. Tedeschi E, Menegazzi M, Yao Y, Suzuki H, Forstermann U, Kleinert H: Green tea inhibits human inducible nitric-oxide synthase expression by downregulating signal transducer and activator of transcription-1alpha activation. Mol Pharmacol 2004, 65:111-120.

32. Mariotto S, Esposito E, Di Paola R, Ciampa A, Mazzon E, de Prati AC, Darra E, Vincenzi S, Cucinotta G, Caminiti R, et al: Protective effect of Arbutus unedo aqueous extract in carrageenan-induced lung inflammation in mice. Pharmacol Res 2008, 57:110-124.

33. De Monchy JG, Kauffman HF, Venge P, Koeter GH, Jansen HM, Sluiter HJ, De Vries K: Bronchoalveolar eosinophilia during allergen-induced late asthmatic reactions. Am Rev Respir Dis 1985, 131:373-376.

34. Diaz P, Gonzalez MC, Galleguillos FR, Ancic P, Cromwell O, Shepherd D, Durham SR, Gleich GJ, Kay AB: Leukocytes and mediators in bronchoalveolar lavage during allergen-induced late-phase asthmatic reactions. Am Rev Respir Dis 1989, 139:1383-1389.

35. Metzger WJ, Richerson HB, Worden K, Monick M, Hunninghake GW: Bronchoalveolar lavage of allergic asthmatic patients following allergen bronchoprovocation. Chest 1986, 89:477-483.

36. Beasley R, Roche WR, Roberts JA, Holgate ST: Cellular events in the bronchi in mild asthma and after bronchial provocation. Am Rev Respir Dis 1989, 139:806-817.

37. Gleich GJ: Mechanisms of eosinophil-associated inflammation. J Allergy Clin Immunol 2000, 105:651-663.

38. Wu W, Samoszuk MK, Comhair SA, Thomassen MJ, Farver CF, Dweik RA, Kavuru MS, Erzurum SC, Hazen SL: Eosinophils generate brominating oxidants in allergen-induced asthma. J Clin Invest 2000, 105:1455-1463,

39. Busse WW: The role of leukotrienes in asthma and allergic rhinitis. Clin Exp Allergy 1996, 26:868-879.

40. Lee T, Lenihan DJ, Malone B, Roddy LL, Wasserman SI: Increased biosynthesis of platelet-activating factor in activated human eosinophils. J Biol Chem 1984, 259:5526-5530.

41. Chung KF, Barnes PJ: Cytokines in asthma. Thorax 1999, 54:825-857. 
42. Mattes J, Yang M, Mahalingam S, Kuehr J, Webb DC, Simson L, Hogan SP, Koskinen A, McKenzie AN, Dent LA, et al: Intrinsic defect in T cell production of interleukin (IL)-13 in the absence of both IL-5 and eotaxin precludes the development of eosinophilia and airways hyperreactivity in experimental asthma. J Exp Med 2002, 195:1433-1444.

43. Fahy JV, Kim KW, Liu J, Boushey HA: Prominent neutrophilic inflammation in sputum from subjects with asthma exacerbation. J Allergy Clin Immunol 1995, 95:843-852.

44. Jatakanon A, Uasuf C, Maziak W, Lim S, Chung KF, Barnes PJ: Neutrophilic inflammation in severe persistent asthma. Am J Respir Crit Care Med 1999, 160:1532-1539.

45. Macdowell AL, Peters SP: Neutrophils in asthma. Curr Allergy Asthma Rep 2007, 7:464-468.

\section{Pre-publication history}

The pre-publication history for this paper can be accessed here: http://www.biomedcentral.com/1472-6882/11/80/prepub

doi:10.1186/1472-6882-11-80

Cite this article as: Chang et al:: Inhibitory effects of inhaled complex traditional Chinese medicine on early and late asthmatic responses induced by ovalbumin in sensitized guinea pigs. BMC Complementary and Alternative Medicine 2011 11:80.

\section{Submit your next manuscript to BioMed Central} and take full advantage of:

- Convenient online submission

- Thorough peer review

- No space constraints or color figure charges

- Immediate publication on acceptance

- Inclusion in PubMed, CAS, Scopus and Google Scholar

- Research which is freely available for redistribution

Submit your manuscript at www.biomedcentral.com/submit 